\title{
Wind and wave energy resource of Germany reported by ERA- Interim reanalysis data
}

\author{
Eugen Rusu and Florin Onea* \\ Department of Mechanical Engineering, “Dunarea de Jos”' University of Galati, Domneasca” Street, 47, Galati 800008, Romania
}

\begin{abstract}
The aim of this work is to identify the most suitable offshore wind farms from Germany that present relevant wave conditions, suitable for the development of a wave energy project. By using the ERAInterim data (wind and waves) reported for the time interval from 1999 and 2018, was possible to identify the more important areas, by taking also into account the seasonal distributions. Several wave energy converters were considered for assessment, for which a capacity factor located between $2.5 \%$ and $14 \%$ was reported, better results being accounted by the Seabased system (rated at $15 \mathrm{~kW}$ ). Finally, we can concluded that the North Sea represent an important area in terms of the marine energy and since at this moment there are operational wave projects, this will represent a suitable area for the development of a mixed wind-wave project.
\end{abstract}

\section{Introduction}

On a European energy market, there is a growing interest for the renewable energy solutions, and one of the most promising sector is related to the marine areas. At this moment a significant amount of research and investments are being put into the offshore wind and wave energy, each sector reporting various levels of development [1]. The offshore wind industry is more mature, as in the case of Germany were 25 projects were operational at the end of 2018. A cumulated capacity of $6380 \mathrm{MW}$ is provide by 1305 wind turbines, from which approximately 136 units were connected in 2018, which were mainly related to the projects Borkum Riffgrund II (464.8 MW) and Arkona (384 MW), respectively. From a financial point of view, only in 2018 approximately 0.4 $€ B N$ were invested in the offshore wind projects from Germany [2].

In order to accelerate the development of the wave energy sector, one solution will be to use the infrastructure of the existing offshore projects in order to develop mixed wind-wave projects [3-5]. In this way, will be possible to extract two energy source from a single location, being also possible to provide some effective coastal protection in some situations [6]. The North Sea seems to represent an important area for the development of the Wave Energy Converter (WECs), this being the case of the NEMOS system (Germany) [7], Wavestar (Denmark) [8] or Wave Dragon (Denmark) [9]. The SINN Power wave energy converter [10] is another system developed in Germany, being reported two ongoing commercial projects.

At this moment, there are various approaches to evaluate the wind and wave resources from the marine areas, from which we can mention the use of numerical models. This is the case of the marine conditions from the coastal waters of Germany (North and Baltic seas) were throughout some reanalysis databases, different meteorological patterns were identified [11-13].

\section{Methods and materials}

The target area considered for evaluation is related to the nearshore and offshore waters from the vicinity of Germany. Most of the offshore wind farms operate in the North Sea, which is also defined by more important wave resources than in the case of the Baltic Sea, and therefore for the present work only the projects from this region will be taken into account. A short presentation of the selected project is provided in Table 1 .

Table 1. Overview of some German offshore wind projects operating in the North Sea [14].

\begin{tabular}{|c|c|c|}
\hline Site & $\begin{array}{c}\text { Project } \\
\text { capacity } \\
\text { (MW) }\end{array}$ & $\begin{array}{c}\text { Number of } \\
\text { turbines }\end{array}$ \\
\hline P1 - Alpha Ventus & 60 & 12 \\
\hline P2 - Amrumbank West & 302 & 80 \\
\hline P3 - BARD Offshore 1 & 400 & 80 \\
\hline P4 - Butendiek & 288 & 80 \\
\hline P5 - DanTysk & 288 & 80 \\
\hline P6 - Global Tech I & 400 & 80 \\
\hline P7 - Gode Wind 1 \& 2 & 582 & 97 \\
\hline P8 - Nordsee One & 332 & 54 \\
\hline P9 - Riffgat & 108 & 30 \\
\hline P10 - Sandbank & 288 & 72 \\
\hline
\end{tabular}


The wind and wave parameters considered in this work are: the wind speed reported at $10 \mathrm{~m}$ height above sea level (U10); the significant wave height (Hs) and the mean wave period (Te). They are related to the ERAInterim dataset, which is a project maintained by the European Centre for Medium-range Weather Forecast.

In order to assess the local variations, it was considered for processing two datasets that covers the 20-year time interval (1999-2018), being defined by four data per day (corresponding to 00-06-12-18 UTC) and by a spatial resolution of $0.1250 \times 0.1250$, which is the finest grid available on the ECMWF server (https://www.ecmwf.int/en/forecasts/datasets/reanalysisdatasets/era-interim).

In general for a renewable project, the wind conditions are evaluated at a $80 \mathrm{~m}$ height (U80) and therefore the ERA-Interim conditions will be adjusted as follows $[15,16]$ :

$$
U 80=U 10 \frac{\ln \left(z_{80}\right)-\ln \left(z_{10}\right)}{\ln \left(z_{10}\right)-\ln \left(z_{0}\right)}
$$

where, U80 - wind speed at $80 \mathrm{~m}, \mathrm{U10}$ - initial wind speed (at $10 \mathrm{~m}), z_{0}$ - roughness of the sea surface $(0.0002 \mathrm{~m}),{ }^{z_{10}}$ and $z_{80}$ - reference heights.

The wave energy flux (Jwave in $\mathrm{W} / \mathrm{m}$ ), associated with to the deep water areas is defined as [17]:

$$
J_{\text {wave }}=\frac{\rho_{\text {water }} g^{2}}{64 \pi} T_{e} H_{s}^{2}
$$

$\rho_{\text {water }}\left(\mathrm{kg} / \mathrm{m}^{3}\right)$ - seawater density, $g(\mathrm{~m} / \mathrm{s}) \quad-$ gravitational acceleration.

Several wave converters will be considered for assessment, their characteristics being indicated in Table 2. The rated powers of the selected WECs cover a larger range of values (from $15 \mathrm{~kW}$ to $7000 \mathrm{~kW}$ ), being possible to estimate in this way the performances of various devices.

Table 2. Technical specifications of the considered WECs $[17,18]$.

\begin{tabular}{|c|c|c|}
\hline $\begin{array}{c}\text { WEC } \\
\text { (rated capacity) }\end{array}$ & $\begin{array}{c}\text { Hs bins } \\
\text { (in meters) }\end{array}$ & $\begin{array}{c}\boldsymbol{T e} \text { bins } \\
\text { (in seconds) }\end{array}$ \\
\hline $\begin{array}{c}\text { Seabased } \\
(15 \mathrm{~kW})\end{array}$ & $1: 0.5: 7$ & $4: 1: 16$ \\
\hline $\begin{array}{c}\text { Pelamis } \\
(750 \mathrm{~kW})\end{array}$ & $0.5: 0.5: 8$ & $5: 0.5: 13$ \\
\hline $\begin{array}{c}\text { Wave Dragon } \\
(7000 \mathrm{~kW})\end{array}$ & $1: 1: 7$ & $5: 1: 17$ \\
\hline
\end{tabular}

The expected power generated by a WEC can be estimated as follows [6]:

$$
P_{E}=\sum_{i=1}^{n_{T}} \sum_{j=1}^{n_{H}} p_{i j} \cdot P_{i j}
$$

where $p_{i j}$ is related to the energy percentage associated to the bin defined by the line $i$ and column $j$, where as $P_{i j}$ is the expected electric power output defined in the power matrix of each WEC for the same bin (defined by line $i$ and column $j$ ).

Figure 1 presents the power matrix of the Wave Dragon system, from which we can identify the expected power output for different sea states combination.

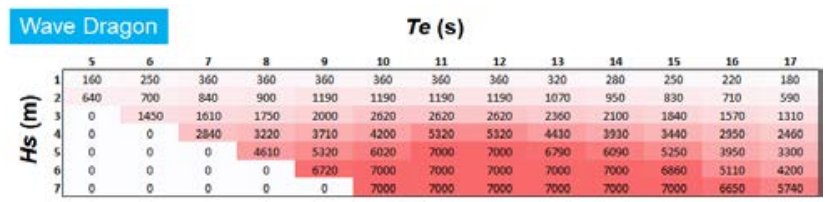

Figure 1. Wave Dragon (7000 kW) power matrix [19]

\section{Results}

In Figure 2 and Figure 3, are presented the spatial distributions of the wind speed (U80) and wave energy flux, where with yellow was indicated the German land area. From the analysis of the wind conditions, much higher conditions seems to be reported in the North Sea where the wind speed may reach maximum of $11 \mathrm{~m} / \mathrm{s}$. Regarding the German areas located in the Baltic Sea, we may expect much lower resources that vary between $7 \mathrm{~m} / \mathrm{s}$ and $9 \mathrm{~m} / \mathrm{s}$, respectively. As for the wave resources, the first thing to notice is that there are reported region with missing data, this aspect being more visible in the case of the Baltic Sea. For the waves associated to the German sector from the North Sea, we may expect an increase of wave energy flux from $4 \mathrm{~kW} / \mathrm{m}$ to $14 \mathrm{~kW} / \mathrm{m}$, as we go from nearshore to offshore.

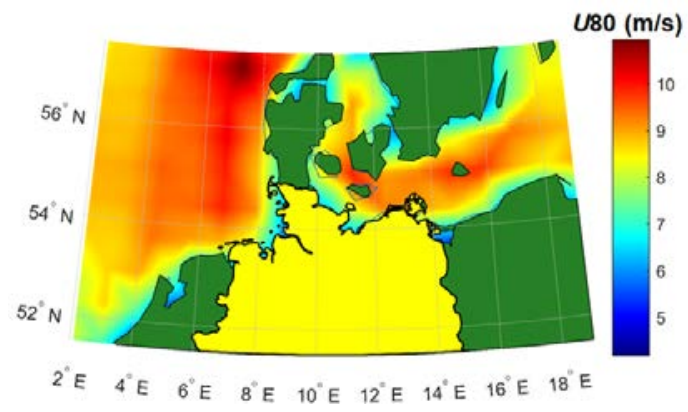

Figure 2. Spatial distribution of the U80 parameter (average values) reported by the ERA-Interim dataset for the 20-year interval (1999-2018).

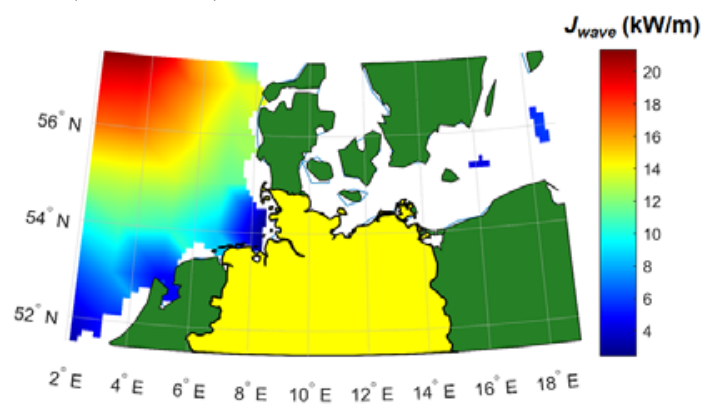

Figure 3. Spatial distribution of the Jwave parameter (average values in $\mathrm{kW} / \mathrm{m}$ ) reported by the ERA-Interim dataset for the 20-year interval (1999-2018). 
Figure 4 illustrates the seasonal variations of the wind speed, by taking into account: a) spring (MarchApril-May); b) summer (June-July-August); c) autumn (September-October-November); d) winter (DecemberJanuary-February). During spring and summer season, a similar spatial distribution is noticed, with the mention that in the case of the first one the wind speed of $8 \mathrm{~m} / \mathrm{s}-9$ $\mathrm{m} / \mathrm{s}$ can also be found between the longitude of $4^{\circ}$ and $6^{\circ}$ east. As we go to the winter season, the values start to increase reaching maximum of $13 \mathrm{~m} / \mathrm{s}$ and minimum of $9 \mathrm{~m} / \mathrm{s}$, respectively.
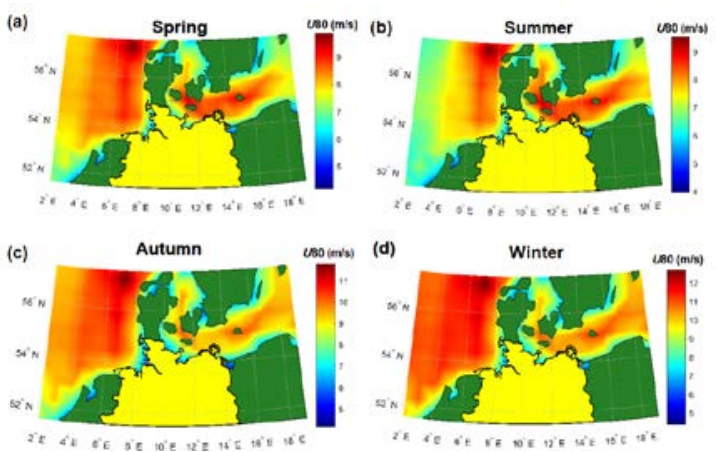

Figure 4. Seasonal distribution of the U80 parameter (average values) reported by the ERA-Interim dataset for the 20 -year interval (1999-2018).

In Figure 5 is presented a similar analysis, taking into account this time the wave resources. The percentage of missing data is significantly much lower during the autumn-winter interval, but even so, the accuracy of the ERA-Interim data to predict the local wave conditions can be discussed. For the North Sea area, significantly much higher resources are being reported during winter, being expected in the German sector at an average wave regime of $25 \mathrm{~kW} / \mathrm{m}$, compared to only $5 \mathrm{~kW} / \mathrm{m}$ accounted by the summer season. Regarding the Baltic Sea conditions, it seems that the values located in the range of $5 \mathrm{~kW} / \mathrm{m}$ and $10 \mathrm{~kW} / \mathrm{m}$ are representative for the winter time. As for the performances of the WECs, in

Figure 6 presents the power output reported by the systems mentioned in Table 2. At this point, it is important to mention that the project Pelamis is no longer operational, but was taken into account since this was one of the first commercial project. All the selected WECs are designed to operate in offshore areas [20].
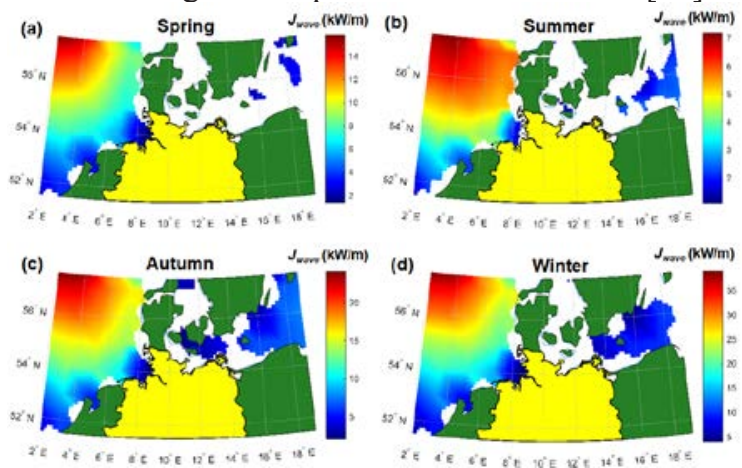

Figure 5. Seasonal distribution of the Jwave parameter (average values in $\mathrm{kW} / \mathrm{m}$ ) reported by the ERA-Interim dataset for the 20-year interval (1999-2018).
From this point of view, the Seabased system report the lowest performances, that are directly associated with the rated power of this device $(15 \mathrm{~kW})$. A maximum of $2.08 \mathrm{~kW}$ is accounted by the site P10 (project Sandbank), while a minimum of $1.22 \mathrm{~kW}$ is reported for P2 (project Amrumbank West). By looking on the values reported by the Pelamis and Wave Dragon, we may notice that some sites stand out in terms of their attractiveness, namely: P1 (Alpha Ventus), P3 (BARD Offshore 1), P5 (DanTysk), P6 (Global Tech I) and P10 (Sandbank).

The capacity factor can be considered as a indicator of efficiency being defined as the ratio between the power produced and the rated power of a particular WEC. These values are presented in Figure 7, were a reverse pattern is noticed compared to the power distribution. A maximum capacity of $14 \%$ may be expected from Seabased, that in general reveal an average of $11 \%$ (per site group), compared to $7.8 \%$ reported for Pelamis and 5\% for Wave Dragon.

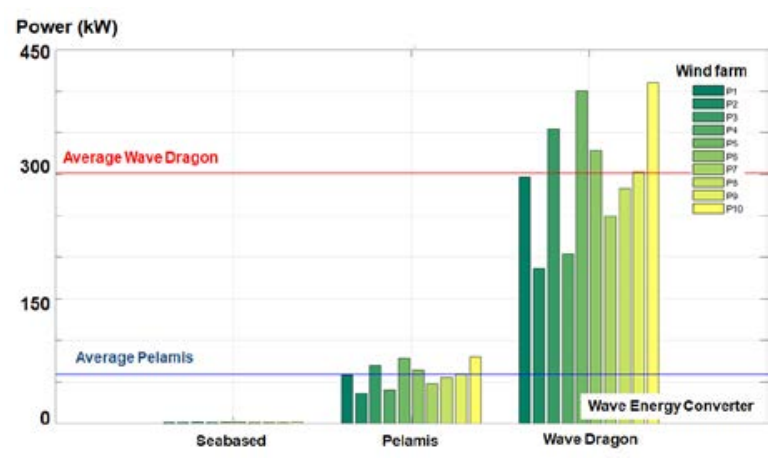

Figure 6. Expected power output (in $\mathrm{kW}$ ) from the Seabased, Pelamis and Wave Dragon system reported for the locations of the offshore wind farms indicated in Table 1.

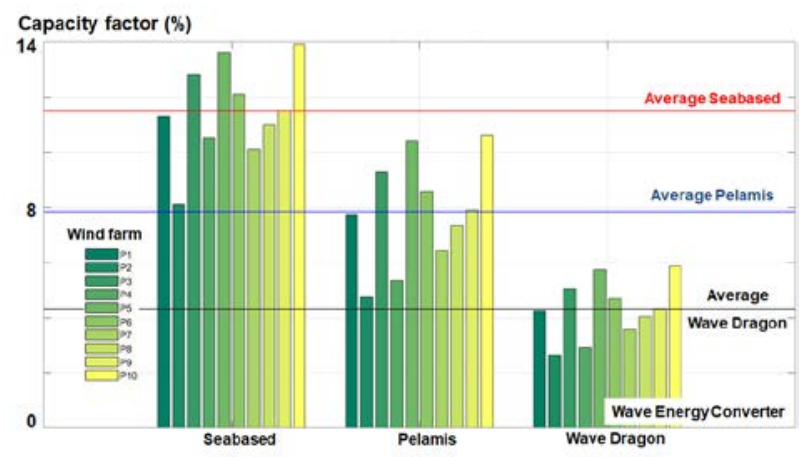

Figure 7. Capacity factor (in \%) associated to the Seabased, Pelamis and Wave Dragon systems. Values reported for the locations of the offshore wind farms indicated in Table 1.

\section{Conclusions}

In the present work a general perspective of the offshore wind and wave resources from the coastal waters of Germany was provided, by taking also into account the performances of some wave energy converters that may operate in the vicinity of some wind projects.

In terms of quality, the wind data reveal better results being not affected by the presence of missing data as in the case of wave, more consistent resources being reported in the North Sea, were an average of $11 \mathrm{~m} / \mathrm{s}$ 
may be noticed (full time distribution). The accuracy of the selected dataset can be discussed, especially in the case of the Baltic Sea, and probably for this type of environment will be more suitable the implementation of a regional wave model. Nevertheless, if we look on the North Sea conditions more promising conditions to implement a mixed wind-wave farm are reported by the sites P10 (Sandbank - 288 MW), P5 (DanTysk - 288 $\mathrm{MW}$ ) and P3 (BARD Offshore $1-400 \mathrm{MW}$ ), respectively. Finally, we can concluded that these wind farms can easily support the development of a wave project taken into account their large capacities and also the fact that in the basin of North Sea, there is interest for the development of wave energy sector.

\section{Acknowledgments}

This work was carried out in the framework of the research project REMARC (Renewable Energy extraction in MARine environment and its Coastal impact), supported by the Romanian Executive Agency for Higher Education, Research, Development and Innovation Funding - UEFISCDI, grant number PN-III-P4-IDPCE-2016-0017. The ERA-Interim data used in this study have been obtained from the ECMWF data server.

\section{References}

[1] C.V.C. Weiss, R. Guanche, B. Ondiviela, O.F. Castellanos, J. Juanes, Marine renewable energy potential: A global perspective for offshore wind and wave exploitation, Energy Conversion and Management. $\quad 177 \quad$ (2018) 43-54. doi:10.1016/j.enconman.2018.09.059.

[2] Offshore wind in Europe - key trends and statistics 2018, WindEurope. (2019). https://windeurope.org/aboutwind/statistics/offshore/european-offshore-windindustry-key-trends-statistics-2018/ (accessed March 8, 2019).

[3] F. Onea, S. Ciortan, E. Rusu, Assessment of the potential for developing combined wind-wave projects in the European nearshore, Energy Environ. 28 (2017) 580-597. doi:10.1177/0958305X17716947.

[4] F. Onea, E. Rusu, Sustainability of the Reanalysis Databases in Predicting the Wind and Wave Power along the European Coasts, Sustainability. 10 (2018) 193. doi:10.3390/su10010193.

[5] E. Rusu, F. Onea, Joint Evaluation of the Wave and Offshore Wind Energy Resources in the Developing Countries, Energies. $10 \quad$ (2017) 1866. doi:10.3390/en10111866.

[6] F. Onea, E. Rusu, The expected efficiency and coastal impact of a hybrid energy farm operating in the Portuguese nearshore, Energy. 97 (2016) 411423. doi:10.1016/j.energy.2016.01.002.
[7] Wave Energy, NEMOS. (n.d.). https://www.nemos.org/waveenergy (accessed May 8, 2019).

[8] E.J. Ransley, D.M. Greaves, A. Raby, D. Simmonds, M.M. Jakobsen, M. Kramer, RANS-VOF modelling of the Wavestar point absorber, Renewable Energy. 109 (2017) 49-65. doi:10.1016/j.renene.2017.02.079.

[9] J.P. Kofoed, P. Frigaard, E. Friis-Madsen, H.Chr. Sørensen, Prototype testing of the wave energy converter wave dragon, Renewable Energy. 31 (2006) 181-189. doi:10.1016/j.renene.2005.09.005.

[10] SINN Power | Wave Energy, SINN Power | Wave Energy. (n.d.). https://www.sinnpower.com (accessed May 8, 2019).

[11]T. Lorenz, I. Barstad, A dynamical downscaling of ERA-Interim in the North Sea using WRF with a $3 \mathrm{~km}$ grid-for wind resource applications, Wind Energy. 19 (2016) 1945-1959. doi:10.1002/we.1961.

[12] N. Groll, R. Weisse, . A multi-decadal wind-wave hindcast for the North Sea 1949-2014: coastDat2, Earth Syst. Sci. Data. 9 (2017) 955-968. doi:10.5194/essd-9-955-2017.

[13]L. Tuomi, A. Sarkanen, Wave forecasts for the Baltic Sea using ECMWF wind fields as forcing data, Ieee, New York, 2008.

[14]4C Offshore Overview - 4C Offshore, (n.d.). https:/www.4coffshore.com/ (accessed March 12, 2019).

[15]A. Raileanu, F. Onea, E. Rusu, Assessment of the Wind Energy Potential in the Coastal Environment of Two Enclosed Seas, Ieee, New York, 2015.

[16]F. Onea, E. Rusu, Efficiency assessments for some state of the art wind turbines in the coastal environments of the Black and the Caspian seas, Energy Explor. Exploit. 34 (2016) 217-234. doi:10.1177/0144598716629872.

[17]E. Rusu, F. Onea, An assessment of the wind and wave power potential in the island environment, Energy. $175 \quad$ (2019) 830-846. doi:10.1016/j.energy.2019.03.130.

[18]J. Morim, N. Cartwright, M. Hemer, A. EtemadShahidi, D. Strauss, Inter- and intra-annual variability of potential power production from wave energy converters, Energy. 169 (2019) 1224-1241. doi:10.1016/j.energy.2018.12.080.

[19]D. Silva, E. Rusu, C. Soares, D. Silva, E. Rusu, C.G. Soares, Evaluation of Various Technologies for Wave Energy Conversion in the Portuguese Nearshore, Energies. 6 (2013) 1344-1364. doi:10.3390/en6031344.

[20]L. Rusu, F. Onea, The performance of some stateof-the-art wave energy converters in locations with the worldwide highest wave power, Renew. Sust. Energ. Rev. 75 (2017) 1348-1362. doi:10.1016/j.rser.2016.11.123. 